\title{
The prognostic impact of tet oncogene family member 2 mutations in patients with acute myeloid leukemia: a systematic- review and meta-analysis
}

\author{
Ruiqi Wang ${ }^{1,2}$, Xiaoning Gao ${ }^{1 *}$ (D) and Li Yu ${ }^{1,3^{*}}$
}

\begin{abstract}
Background: The impact of Tet oncogene family member 2 (TET2) mutations on the prognosis of acute myeloid leukemia (AML) is still controversial. A meta analysis is needed in order to assess the prognostic significance of TET2 mutation in AML.

Methods: Five databases including PubMed, Cochrane, EMBase, China National Knowledge Internet (CNKI) and Wanfang database were retrieved to search studies that investigated the correlation between TET2 mutations and outcomes of AML patients. Pooled hazard ratios (HRs) and odds ratios (ORs) were used to assess the effects of TET2 mutations.

Results: Sixteen studies were included. TET2 mutation was an unfavorable prognostic factor for overall survival (OS: $H R=1.386 ; P<0.001)$ and event-free survival (EFS: HR $=1.594 ; P=0.002)$ in patients with AML. For patients under 65 years of age, TET2 mutation predicted an inferior OS ( $H R=1.310, P=0.051)$ and $E F S(H R=1.429, P=0.027)$. For patients with intermediate-risk cytogenetics (IR-AML), mutant TET2 had a significant association with adverse OS $(H R=0.474 ; P<0.001)$. For patients with normal cytogenetics (CN-AML), mutant TET2 also conferred adverse OS (HR $=1.425 ; P<0.001)$ and $\mathrm{EFS}(\mathrm{HR}=1.450, P<0.001)$. Further, among patients with $\mathrm{CN}-\mathrm{AML}$, mutant TET2 was associated with inferior OS $(H R=2.034, P<0.001)$ and EFS $(H R=2.140, P<0.001)$ in the ELN favorable-risk subgroup and an inferior $\mathrm{EFS}(\mathrm{HR}=1.487 ; P<0.001)$ in the ELN intermediate-Isubgroup. With respect to treatment outcome, TET2 mutation predicted a significantly lower rate of complete remission (CR) in cases with ELN favorable-risk cytogenetics ( $\mathrm{OR}=0.460, P=0.011)$.
\end{abstract}

Conclusions: TET2 mutation had adverse impacts on survival and treatment response in AML patients and will contribute to risk-stratification, prognosis prediction and therapy guidance.

Keywords: TET2 mutation, Acute myeloid leukemia, Prognosis

\section{Background}

Acute myeloid leukemia (AML) is the most common leukemia for its highest incidence in both new cases and deaths in leukemia. But with exploration in AML [1], people have found out several unfavorable factors that influenced the survival of patients with AML, such as cytogenetics, which have been used in risk stratification

\footnotetext{
*Correspondence: gaoxn@263.net; liyu301@vip.163.com

'Department of Hematology, Chinese PLA General Hospital, Medical School of Chinese PLA, 28 Fuxing Road, Beijing 100853, China

Full list of author information is available at the end of the article
}

to predict the prognosis and guide therapeutic strategy [2]. Another kind of factors are genetic mutations, also used in prognostic stratification in the latest ELN risk-stratification, including mutations in genes encoding nucleophosmin 1 (NPM1), CCAAT/enhancer binding protein alpha (CEBPA), tumor protein 53 (TP53) and internal tandem duplication of FMS-like tyrosine kinase 3 (FLT3-ITD) [3].

Besides, mutations involving epigenetics also predict prognosis of AML patients despite they haven't been published on the guideline. For instance, there are plenty of

(c) The Author(s). 2019 Open Access This article is distributed under the terms of the Creative Commons Attribution 4.0 International License (http://creativecommons.org/licenses/by/4.0/), which permits unrestricted use, distribution, and reproduction in any medium, provided you give appropriate credit to the original author(s) and the source, provide a link to the Creative Commons license, and indicate if changes were made. The Creative Commons Public Domain Dedication waiver (http://creativecommons.org/publicdomain/zero/1.0/) applies to the data made available in this article, unless otherwise stated. 
studies demonstrating that mutations in genes encoding DNA methyltransferase 3A (DNMT3A) and additional sex comb-like protein 1 ( $A S X L 1)$ are poor prognostic factors on AML [4-7]. Qingyu Xu clearly upheld the adverse prognostic significance of isocitrate dehydrogenase 1 gene (IDH1) and the favorable prognostic significance of isocitrate dehydrogenase 2 gene $(I D H 2)$ respectively [8]. But tet oncogene family member 2 gene (TET2) still has a controversial prognostic impact on AML because studies researching TET2 mutations are not plenty and their conclusions are not identical. From Hsiao-Wen Kao's study [9], there was no significant difference on survival between patients with and without mutant TET2 while Jay P. Patel developed an integrated classification system and demonstrated that TET2 mutations were associated with shorter overall survival (OS) only among patients divided into intermediate-risk AML (IR-AML) [10]. In a meta-analysis performed by Wenjian Liu, mutant TET2 was an unfavorable prognostic factor among not only entire AML patients but also favorable and intermediate-I subgroups based on ELN guidelines [11]. Since this meta analysis only contained 8 studies, it's necessary to perform a updated meta analysis containing more studies to further explore the influence of TET2 mutations on clinical outcome and survival in AML patients.

On the other hand, TET2 has a function of converting 5-methyl-cytosine (5-mc) to 5-hydroxymethyl-cytosine (5-hmc), thus, mutant TET2 could disorder the function of hematopoietic stem cell through epigenetic modification [12]. Drugs aiming at epigenetic mechanism have served in clinical therapy and provided a lot of benefits to patients with AML [13-16]. If the prognostic significance of TET2 mutations can be clearly evaluated, it will be beneficial to direct individual therapeutic strategies.

\section{Methods}

\section{Inclusion and exclusion criteria}

Entitled studies should content following requirements: (i) constrained to human studies demonstrating the prognostic influence of mutant TET2 on adult patients with AML. (ii) contained data in the aspect of survival and treatment outcome, (iii) published in English. Exclusion criteria were as followings: (i) focusing on pediatric AML, (ii) data which were not available or sufficient, (iii) study cohort overlapped, (iv) reviews and meta-analysis.

\section{Literature review}

We implemented a literature search on electronic databases of PubMed, Cochrane, Embase together with Chinese databases comprising of China National Knowledge Internet and WanFang database, without limitations in publication date and regions. Terms for searching included "AML" "acute myeloid leukemia"
"TET2" "tet oncogene family member 2". References of articles we searched were also used in literature search.

Titles and abstracts of initially selected studies were reviewed depending on inclusion and exclusion criteria. Once contradictions occurred, they would be solved by discussion. After articles meeting demands were chosen, their full-texts would be scanned to distinguish appropriate studies and quality assessment according to Newcastle-Ottawa Scale would be used in the final procedure to determine the studies that could be included in our meta-analysis.

\section{Data extraction}

Relevant information was extracted from ultimately determined studies and summarized. Basic extracted information included authors of studies, publication year, publication journal, region, sample size of cases, frequency of mutant TET2, median age of study cohort, detecting method, cohort type and therapy regimen, while clinical information contained sex ratio, laboratory results, French-American-British classification, cytogenetic risk classification, incidences of normal karyotype and complex karyotype and incidences of common genetic mutations (NPM1, FLT3-ITD, DNMT3A, IDH, CEBPA, $A S X L 1)$. Survival-related data were also extracted, including odds ratio (OR) for complete remission (CR) rates (or the cases achieving $\mathrm{CR}$ in patients with and without mutant TET2) and the hazard ratio (HR) for OS, event-free survival (EFS). Data from multivariate analyses were extracted with priority, but data from univariate analyses or calculated from Kaplan-Meier survival curves were also used in our meta-analysis when multivariate results were not available [17]. With respect to extraction of survival curves, we applied the software Engauge Digitizer 4.1 in this part. After inputting the pictures of survival curves and outputting the data of specific spots on curves, we used Excel to calculate HR and relevant data.

\section{Statistical analysis}

We used STATA 12.0 statistical software to analyze the data extracted. TET2 mutation was identified as relating to an unfavorable treatment outcome or survival when pooled ORs below or HRs over 1.000, which became statistically significant if $95 \%$ confidence interval (CI) did not cover 1.000 or a $P$ value less than 0.05 .

As for heterogeneity, Q test was used to measure it. I-square $\left(\mathrm{I}^{2}\right)<30 \%, 30-50 \%, 50-75$, and $>75 \%$ meant low, moderate, substantial and considerable heterogeneity relatively [18]. Additionally, $P<0.10$ represented a significant heterogeneity [19]. Random effect model was used for a significant heterogeneity observed, while fixed effect model was for studies without or with slight heterogeneity. Sensitivity test was used to determine the source of heterogeneity and 
evaluate the stability of results. Subgroup analyses were performed to evaluate the results in aspects of publication year, data type, region, study cohort, median age of patients as well as detecting method. Egger and Begg tests were used to assess publication bias, a $P$ value less than 0.05 representing existence of publication bias.

\section{Results}

\section{Selection procedure}

At first, 686 studies were obtained from 5 databases, and we excluded 80 records because of duplication. Then we scanned the titles and abstracts of the remaining articles and removed 549 articles for no association with our study purpose. We read the full texts of the rest articles next and removed 41 studies due to the following reasons: 5 studies for focusing on pediatric AML, 7 studies for overlapped cohorts, 4 studies for reviews and meta-analysis, and 25 studies with incomplete data. Ultimately, there were 16 studies selected for our study. The selection procedure was illustrated in Fig. 1.

\section{Study characteristics}

Characteristics of 16 studies with a total of 4378 cases were shown in Table 1: 4 of them from America, 6 from Europe, 5 from Asia, and one involving multiple regions [9, 10, 20-33]. TET2 mutation had a frequency varying from 6.05 to $27.36 \%$ in AML patients and from 6.05 to $36.23 \%$ in patients with normal cytogenetics (CN-AML). Mutational frequency refers to the proportion of patients harboring TET2 mutations.

Eleven out of 16 studies revealed that TET2 mutations were distributed throughout the whole coding exon detected with no specific hot spots (Additional file 2: Table S1) $[9,22-30,32]$. TET2 mutation was significantly associated with older age in 7 studies $[9,21,24,25,27,30$, 33], higher white blood cell (WBC) count in 5 studies $[21,24,25,27,30]$, higher hemoglobin level in 2 studies $[30,33]$ and with lower platelet count in 4 studies (Additional file 3: Table S2) $[25,27,28,30]$. Besides, one study showed that TET2 mutations were rarer in M3 whereas another showed TET2 mutation was more frequent in M4 with respect to FAB classification [25, 28]. The others didn't show any relationship between mutant TET2 and FAB subtypes (Additional file 3: Table S3). In

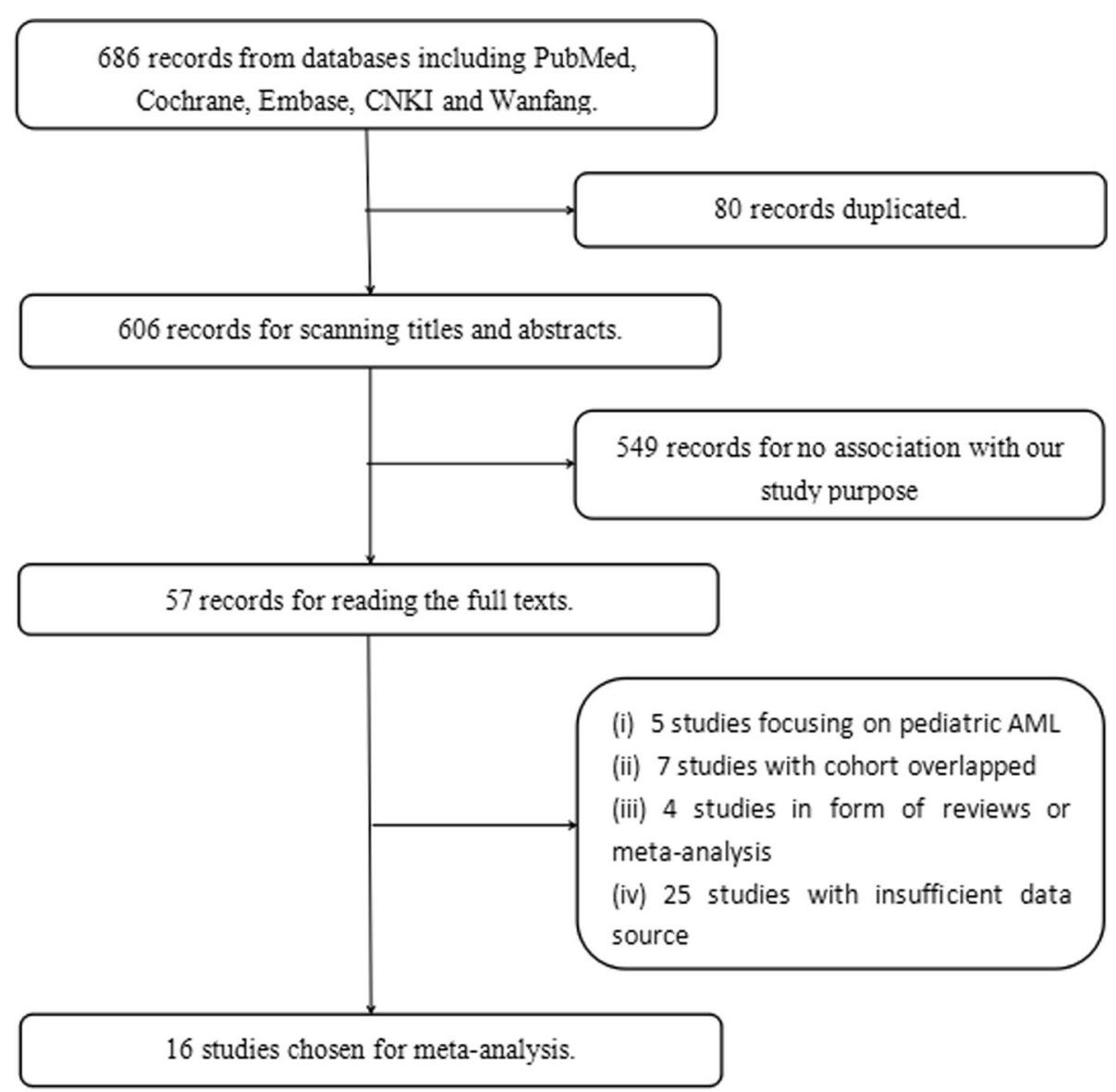

Fig. 1 Flow chart of the study selection. CNKI, China National Knowledge Internet; AML, acute myeloid leukemia 
Table 1 Characteristics of studies selected in the meta-analysis

\begin{tabular}{|c|c|c|c|c|c|c|c|c|c|c|c|}
\hline Study & Year & NOS & Journal & Region & $\begin{array}{l}\text { Total } \\
\text { number }\end{array}$ & TET2m & $\begin{array}{l}\text { Median } \\
\text { age }\end{array}$ & $\begin{array}{l}\text { Detecting } \\
\text { method }\end{array}$ & Data type & Therapy regimen & $\begin{array}{l}\text { Cohort } \\
\text { type }\end{array}$ \\
\hline Wahab & 2009 & 7 & Blood & America & 91 & 11 & 65 & Unknown & $\begin{array}{l}\text { Calculated } \\
\text { from K-M } \\
\text { curves }\end{array}$ & Unknown & AML \\
\hline Nibourel & 2010 & 6 & Blood & France & 111 & 19 & 43 & $\begin{array}{l}\text { Direct } \\
\text { sequencing }\end{array}$ & $\begin{array}{l}\text { Calculated } \\
\text { from K-M } \\
\text { curves }\end{array}$ & $\begin{array}{l}\text { Anthracycline-cytosine } \\
\text { arabinoside induction } \\
\text { treatment followed by HDAC } \\
\text { consolidation or allo-HSCT }\end{array}$ & AML \\
\hline Metzeler & 2011 & 9 & $\begin{array}{l}\text { Journal of } \\
\text { Clinical } \\
\text { Oncology }\end{array}$ & America & 418 & 95 & $>60$ & $\begin{array}{l}\text { Direct } \\
\text { sequencing }\end{array}$ & $\begin{array}{l}\text { Calculated } \\
\text { from K-M } \\
\text { curves }\end{array}$ & Standard intensive therapy & CN-AML \\
\hline Kosmider & 2011 & 7 & Haematologica & France & 247 & 49 & 66 & $\begin{array}{l}\text { Direct } \\
\text { sequencing }\end{array}$ & $\begin{array}{l}\text { Unitivariate } \\
\text { or } \\
\text { calculated } \\
\text { from K-M } \\
\text { curves }\end{array}$ & $\begin{array}{l}\text { Intensive chemotherapy with } \\
\text { anthracycline-cytarabine }\end{array}$ & s-AML \\
\hline Chou & 2011 & 7 & Blood & China & 486 & 64 & 51.5 & Unknown & $\begin{array}{l}\text { Multivariate } \\
\text { and } \\
\text { calculated } \\
\text { from K-M } \\
\text { curves }\end{array}$ & $\begin{array}{l}\text { Standard intensive therapy or } \\
\text { palliativecare or low-dose } \\
\text { chemotherapy }\end{array}$ & AML \\
\hline Patel & 2012 & 8 & $\begin{array}{l}\text { The New } \\
\text { England } \\
\text { Journal of } \\
\text { Medicine }\end{array}$ & America & 391 & 33 & $<60$ & $\begin{array}{l}\text { Direct } \\
\text { sequencing }\end{array}$ & $\begin{array}{l}\text { Calculated } \\
\text { from K-M } \\
\text { curves }\end{array}$ & $\begin{array}{l}\text { Induction therapy with high } \\
\text { or standard dose of DNR }\end{array}$ & AML \\
\hline Weissmann & 2012 & 7 & Leukemia & Germany & 318 & 87 & 66.4 & $\begin{array}{l}\text { Next- } \\
\text { generation } \\
\text { sequencing }\end{array}$ & $\begin{array}{l}\text { Calculated } \\
\text { from K-M } \\
\text { curves }\end{array}$ & Unknown & AML \\
\hline Gaidzik & 2012 & 8 & $\begin{array}{l}\text { Journal of } \\
\text { Clinical } \\
\text { Oncology }\end{array}$ & Germany & 783 & 60 & $<60$ & $\begin{array}{l}\text { Direct } \\
\text { sequencing }\end{array}$ & $\begin{array}{l}\text { Calculated } \\
\text { from K-M } \\
\text { curves }\end{array}$ & Double induction therapy & AML \\
\hline Renneville & 2014 & 6 & Oncotarget & France & 139 & 19 & 62 & $\begin{array}{l}\text { Direct } \\
\text { sequencing }\end{array}$ & Univariate & $\begin{array}{l}\text { Standard front-line chemo } \\
\text { therapy with or without low- } \\
\text { dose gemtuzumab } \\
\text { ozogamicin }\end{array}$ & CN-AML \\
\hline Damm & 2014 & 8 & $\begin{array}{l}\text { Genes } \\
\text { Chromosomes } \\
\text { and Cancer }\end{array}$ & $\begin{array}{l}\text { France } \\
\text { and } \\
\text { Germany }\end{array}$ & 215 & 13 & $<60$ & $\begin{array}{l}\text { Direct } \\
\text { sequencing }\end{array}$ & multivariate & $\begin{array}{l}\text { Intensive double induction } \\
\text { and consolidation therapy }\end{array}$ & CN-AML \\
\hline Tian & 2014 & 7 & $\begin{array}{l}\text { International } \\
\text { Journal of } \\
\text { Hematology }\end{array}$ & Asia & 373 & 60 & 45 & $\begin{array}{l}\text { Direct } \\
\text { sequencing }\end{array}$ & $\begin{array}{l}\text { Calculated } \\
\text { from K-M } \\
\text { curves }\end{array}$ & $\begin{array}{l}\text { Standard induction therapy } \\
\text { followed by consolidation of } \\
\text { HDAC or allo-HSCT }\end{array}$ & CN-AML \\
\hline S.Ohgami & 2015 & 7 & $\begin{array}{l}\text { Modern } \\
\text { Pathology }\end{array}$ & America & 93 & 6 & 55 & $\begin{array}{l}\text { Next- } \\
\text { generation } \\
\text { sequencing }\end{array}$ & Muitivariate & $\begin{array}{l}\text { Standard induction therapy } \\
\text { with cytarabine and } \\
\text { danorubicin or idarubicin }\end{array}$ & AML \\
\hline Ahn & 2015 & 9 & Haematologica & $\begin{array}{l}\text { Multiple } \\
\text { region }\end{array}$ & 407 & 54 & 52 & $\begin{array}{l}\text { Direct } \\
\text { sequencing }\end{array}$ & Muitivariate & Standard induction therapy & CN-AML \\
\hline Kao & 2015 & 8 & Oncotarget & China & 98 & 18 & 55 & $\begin{array}{l}\text { Direct } \\
\text { sequencing }\end{array}$ & $\begin{array}{l}\text { Calculated } \\
\text { from K-M } \\
\text { curves }\end{array}$ & $\begin{array}{l}\text { Standard intensive therapy } \\
\text { with daunomycin and } \\
\text { cytarabine }\end{array}$ & $\begin{array}{l}\text { AML } \\
\text { with } \\
\text { MLL- } \\
\text { PTD }\end{array}$ \\
\hline Cher & 2016 & 8 & $\begin{array}{l}\text { Blood Cancer } \\
\text { Journal }\end{array}$ & China & 96 & 8 & 41 & $\begin{array}{l}\text { Next- } \\
\text { generation } \\
\text { sequencing }\end{array}$ & $\begin{array}{l}\text { Multivariate } \\
\text { and } \\
\text { univariate }\end{array}$ & $\begin{array}{l}\text { Induction chemotherapy } \\
\text { comprising cytarabine and } \\
\text { daunorubicin with } \\
\text { consolidation therapy } \\
\text { comprising HDAC or allo-HSCT }\end{array}$ & $\begin{array}{l}\text { CBF- } \\
\text { AML }\end{array}$ \\
\hline Lin & 2016 & 9 & $\begin{array}{l}\text { Cancer } \\
\text { Medicine }\end{array}$ & China & 112 & 12 & 42.6 & $\begin{array}{l}\text { Next- } \\
\text { generation } \\
\text { sequencing }\end{array}$ & Multivariate & $\begin{array}{l}\text { Standard therapy with or } \\
\text { without allo-HSCT }\end{array}$ & AML \\
\hline
\end{tabular}


Abbreviations: NOS the Newcastle-Ottawa-Scale, TET2, tet oncogene family member 2, $m$ mutation, HDAC high-dose cytarabine, allo-HSCT allo hematopoietic stem cell transplantation, $C N-A M L$ cytogenetically normal acute myeloid leukemia, $s-A M L$ secondary acute myeloid leukemia, MLL-PTD partial tandem duplication of mixed-lineage leukemia gene, CBF-AML core-binding factor acute myeloid leukemia

addition, TET2 mutation was more frequent in AML patients with normal karyotype according to two studies $[25,30]$, and there was only one study showing the close association between mutant TET2 and intermediate-risk cytogenetics (Additional file 3: Table S3) [25]. But after a meta-analysis, we found a significantly close relationship between TET2 mutations and intermediate-risk cytogenetics with an OR of 1.765(95\%CI: 1.212-2.569; $P=0.003$; $\left.\mathrm{I}^{2}=39.7 \%, P=0.159\right)$, and TET2 mutations were more infrequent in favorable-risk cytogenetics $(\mathrm{OR}=0.547$, 95\%CI: $\left.0.325-0.920 ; P=0.023 ; \mathrm{I}^{2}=11.2 \%, P=0.337\right)$. As for gene-gene association, a significantly higher frequency of NPM1 mutation was existed in patients with TET2 mutations compared with those with wild type TET2 according to 5 studies $[21,25,28,29,31]$. The same strong relationship was also noted between mutant ASXL1 and mutant TET2 in 3 studies [10, 20, 25]. On the contrary, $I D H$ mutation was mutually excluded with TET2 mutation, which was observed in 7 studies (Additional file 3: Table S5) [9, 10, 24-26, 28, 33], and the pooled OR was 0.123(95\%CI: $0.071-0.212 ; P<0.001)$. Then we conducted meta analyses and explored the exact close association of TET2 mutations with NPM1(OR $=1.735, P<0.001), D N M T 3 A(\mathrm{OR}=2.361, P=$ $0.045)$ and $A S X L 1$ mutations $(\mathrm{OR}=2.743, P=0.009)$.

\section{Prognosis of TET2 mutation in AML}

With respect to response to therapy in AML patients, the combined ORs of TET2 mutation for CR rate were 0.802 (95\%CI: 0.583-1.103; $P=0.176$; heterogeneity: $\mathrm{I}^{2}=0.0 \%, P=0.465$; Fig. 2a). Fifteen studies were included to calculate pooled HRs for OS in AML patients, resulting in the result of 1.480 (95\%CI: 1.241-1.766; $P<$ 0.001; heterogeneity: $\left.\mathrm{I}^{2}=34.3 \%, P=0.094\right)$. With $P<0.1$ in heterogeneity test, we conducted a sensitivity test and found recombined $\mathrm{HRs}$ for OS were 1.386 (95\%CI: 1.217-1.577; $P<0.001$; heterogeneity: $\mathrm{I}^{2}=19.7 \%, P=$ 0.239 ) when Lin's study were excluded (Additional file 1 : Figure S1a-1b). Considering EFS in AML patients, we combined 9 studies and pooled HRs were 1.594 (95\%CI: 1.187-2.141; $P=0.002$; heterogeneity: $I^{2}=56.4 \%, P=$ 0.019; Fig. 2b). We conducted a sensitivity test owing to the significant heterogeneity and that result wasn't altered by omitting any one of the studies. We therefore conducted subgroup analyses to evaluate the result (Table 2). Furthermore, we also explored the impact of mutant TET2 on OS in AML patients under 65 years of age, figuring out a pooled HRs of 1.310 (95\%CI: 0.999-1.718; $P=0.051$; heterogeneity: $\mathrm{I}^{2}=24.6 \%, P=$ 0.264; Fig. 2c), while the pooled HRs for EFS in the same cohort were 1.724 (95\%CI: 1.007-2.954; $P=$
0.047; heterogeneity: $\left.\mathrm{I}^{2}=56.1 \%, P=0.077\right)$ and became 1.429 (95\%CI: $1.041-1.962, P=0.027$; heterogeneity: $\left.\mathrm{I}^{2}=37.4 \%, P=0.202\right)$ after the study of Cher and colleagues was excluded (Additional file 1: Figure S1c-1d). Interestingly, we found that the summary HRs for OS in patients with IR-AML were 1.662 (95\%CI: $1.312-2.105 ; \quad P<0.001$; heterogeneity: $\mathrm{I}^{2}=$

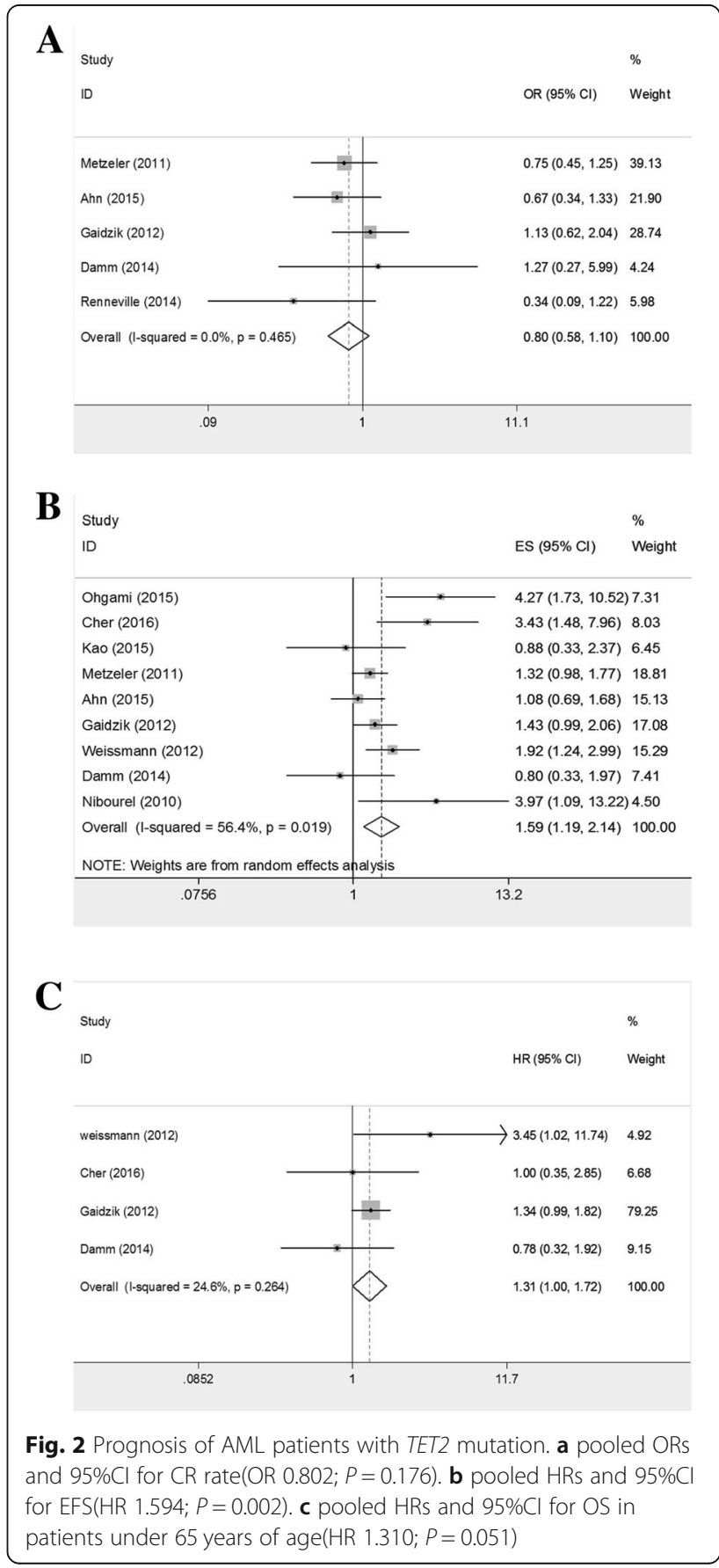


Table 2 Subgourp analyses of EFS on TET2 mutation

\begin{tabular}{|c|c|c|c|c|}
\hline \multicolumn{2}{|l|}{ Variables } & \multirow{2}{*}{$\begin{array}{l}\text { Number of studies, heterogeneity } P^{2} \%, p \\
1\end{array}$} & \multirow{2}{*}{$\begin{array}{l}\text { Pooled HRs }(95 \% \mathrm{Cl}), P \text { value } \\
3.430[1.479-7.955], P=0.004\end{array}$} & \multirow{2}{*}{$\frac{\operatorname{Interaction}(p)}{0.096}$} \\
\hline Year & 2016 & & & \\
\hline & 2015 & $3(74.8), P=0.019$ & $1.320[0.911-1.913], P=0.142$ & \\
\hline & 2014 & 1 & $0.800[0.327-1.955], P=0.624$ & \\
\hline & 2012 & $2(1.7), P=0.313$ & $1.613[1.217-2.138], P=0.001$ & \\
\hline & 2011 & 1 & $1.320[0.982-1.774], P=0.066$ & \\
\hline & 2010 & 1 & $3.970[1.140-13.826], P=0.030$ & \\
\hline \multirow[t]{3}{*}{ Data type } & Multivariate & $3(76.4), P=0.014$ & $1.284[0.891-1.850], P=0.181$ & 0.110 \\
\hline & Calculated from K-M curves & $5(26.2), P=0.247$ & $1.473[1.209-1.794], P<0.001$ & \\
\hline & univariate & 1 & $3.430[1.479-7.955], P=0.004$ & \\
\hline \multirow[t]{4}{*}{ Region } & America & $2(83.0), P=0.015$ & $1.479[1.117-1.959], P=0.006$ & 0.413 \\
\hline & Europe & $4(44.1), P=0.147$ & $1.580[1.215-2.055], P=0.001$ & \\
\hline & Asia & $2(76.4), P=0.040$ & $1.934[1.020-3.667], P=0.043$ & \\
\hline & other & 1 & $1.076[0.688-1.682], P=0.748$ & \\
\hline \multirow[t]{3}{*}{ Cohort } & AML & $2(79.4), P=0.028$ & $1.669[1.189-2.344], P=0.003$ & 0.444 \\
\hline & CN-AML & $5(47.5), P=0.106$ & $1.377[1.120-1.692], P=0.002$ & \\
\hline & Others & $2(76.4), P=0.040$ & $1.934[1.020-3.667], P=0.043$ & \\
\hline \multirow[t]{2}{*}{ Detection methods } & Direct sequencing & $6(13.1), P=0.331$ & $1.283[1.058-1.556], P=0.011$ & 0.002 \\
\hline & Next-generation sequencing & $3(38.3), P=0.198$ & $2.418[1.691-3.459], P<0.001$ & \\
\hline
\end{tabular}

Abbreviations: $H R s$ hazard ratios, $C N-A M L$ cytogenetically normal acute myeloid leukemia

46.1\%, $P=0.046)$, and decreased to $1.474 \quad(95 \% \mathrm{CI}$ : 1.252-1.734; $P<0.001$; heterogeneity: $\mathrm{I}^{2}=17.1 \%, P=$ 0.285 ) with the study of Patel and colleagues omitted (Additional file 1: Figure S1e-1f).

\section{Prognosis of TET2 mutation in CN-AML}

Among patients with $\mathrm{CN}-\mathrm{AML}$, the pooled ORs of TET2 mutation for CR rate were 0.803 (95\% CI: 0.5621.147; $P=0.228$; heterogeneity: $\mathrm{I}^{2}=39.0 \%, P=0.161$; Fig. 3a). Despite the insignificance of ORs for CR rate, integrated HRs for OS were 1.425 (95\%CI: 1.221-1.664; $P<0.001$; heterogeneity: $\mathrm{I}^{2}=0.0 \%, P=0.633$; Fig. 3b), while the pooled HRs for EFS were $1.450(95 \% \mathrm{CI}$ : 1.199-1.754; $P=0.001$; heterogeneity: $\mathrm{I}^{2}=45.1 \%, P=$ 0.105; Fig. 3c).

Among patients with CN-AML under 65 years of age, the pooled HRs for OS were 1.630 (95\%CI: 0.817-3.250; $P=0.166$; heterogeneity: $\left.\mathrm{I}^{2}=54.0 \%, P=0.114\right)$ and became 1.999 (95\%CI: 1.317-3.033, $P=0.001$; heterogeneity: $\mathrm{I}^{2}=0.0 \%, P=0.352$ )(Additional file 1: Figure $\mathrm{S} 2 \mathrm{a}-2 \mathrm{~b}$ ) with Damm's study omitted, while the combined HRs for EFS were 1.741 (95\%CI: $1.180-2.569 ; P=0.005$; heterogeneity: $\mathrm{I}^{2}=47.6 \%, P=0.148$; Fig. $\left.3 \mathrm{~d}\right)$.

\section{Prognosis of TET2 mutation based on ELN risk stratification}

We evaluated the prognosis of TET2 mutation based on ELN risk stratification. Among patients in ELN favorable-risk (CN-AML patients carrying NPM1mutwithout FLT3-ITD and/or CEBPAdouble mut), the combined ORs for CR rate were 0.460 (95\%CI: 0.252-0.840; $P=0.011$; heterogeneity: $\mathrm{I}^{2}=0.0 \%, P=0.405$; Fig. 4a). What's more, the pooled HRs for EFS were 2.140 (95\%CI: 1.476-3.101; $P<0.001$; heterogeneity: $\mathrm{I}^{2}=8.8 \%$, $P=0.334$; Fig. $4 \mathrm{~b})$. The pooled HRs for OS were 2.034 (95\%CI: $1.440-2.872 ; P<0.001$; heterogeneity: $\mathrm{I}^{2}=0.0 \%$, $P=0.797$; Fig. 4c). The results above showed an unfavorable prognostic impact of TET2 mutation in patients of this group. As for patients in ELN intermediate-Irisk group (all remaining patients with $\mathrm{CN}-\mathrm{AML}$ ), the pooled ORs for CR rate were 1.158 (95\%CI: $0.408-3.280 ; P=$ 0.783; heterogeneity: $\left.\mathrm{I}^{2}=70.5 \%, P=0.034\right)$. Hence, we performed a sensitivity test as well although the number of studies included was only three. After excluding the study of Gaidzik and colleagues, the recombined ORs for CR rate decreased to 0.809 (95\%CI: $0.465-1.409$; $P=$ 0.454; heterogeneity: $\mathrm{I}^{2}=45.7 \%, P=0.175$ ) (Additional file 1: Figure S3a-3b). Therefore, this study made up a part of the significant heterogeneity and has to be discussed further. In addition, the pooled HRs for EFS were 1.487 (95\%CI: $1.117-1.978 ; \quad P=0.007$; heterogeneity: $\mathrm{I}^{2}=6.3 \%, P=0.344 ;$ Fig. $\left.4 \mathrm{~d}\right)$.

\section{Sensitivity analysis}

Among patients with AML, the study of Lin and colleagues made up a part of heterogeneity due to its 


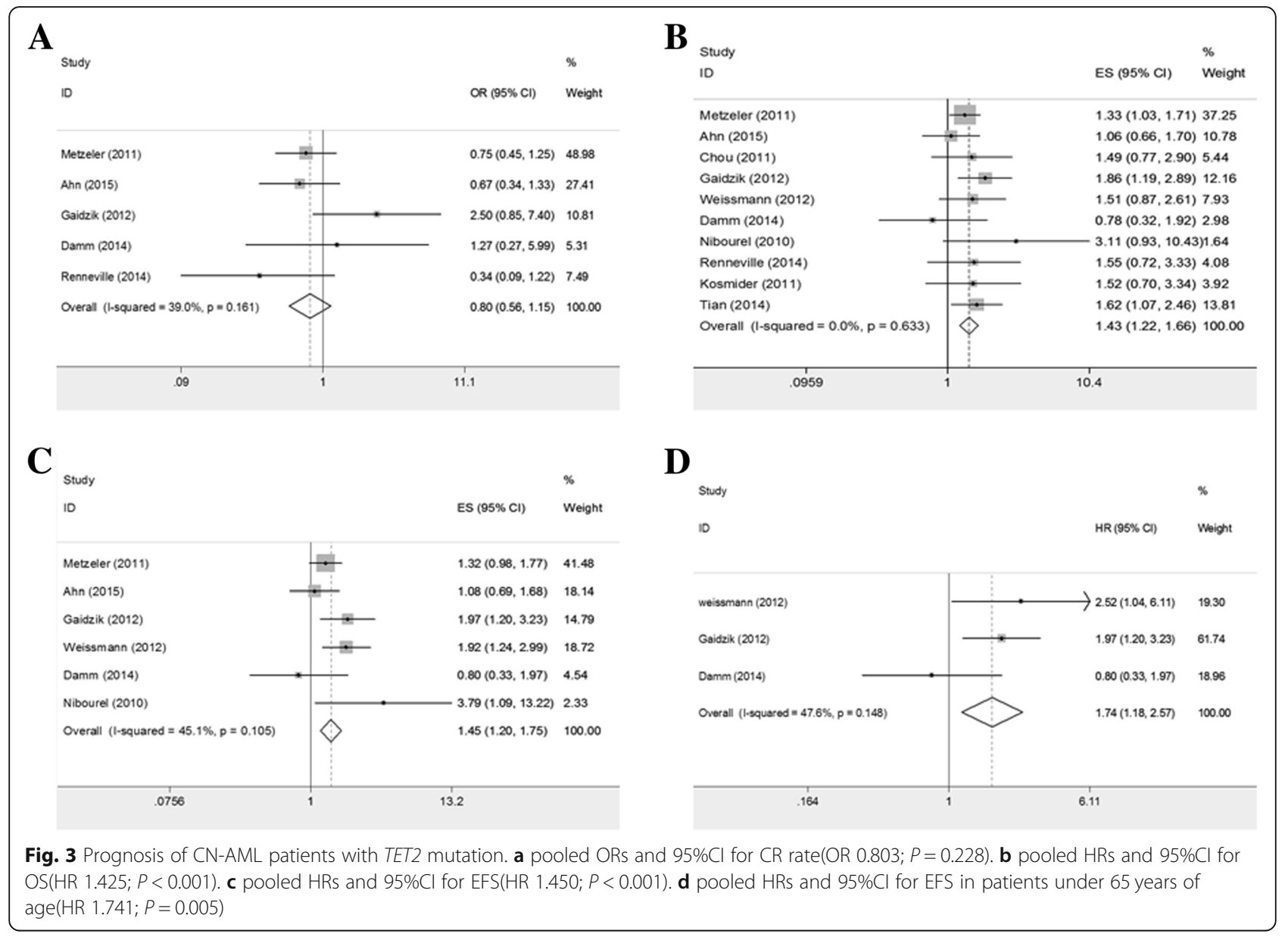

outlier of HR for OS according to the sensitivity test, but it shouldn't be excluded for the following reasons: At first, the sample size of cases from the entire cohort was adequate as well as the number of cases with TET2 mutation; Second, the maximum follow-up period of this study was around 120 months, which was long enough to diminish the bias; Next, the new result didn't change too much with this study omitted, and TET2 mutation still conferred an unfavorable impact on OS in AML patients. Likewise, among patients with IR-AML, the sensitivity test showed that the study of Patel and colleagues was the biggest contribution of heterogeneity in pooled HRs for OS. This study showed a relatively stronger impact of TET2 on OS compared with other studies, but actually there was no need to exclude it due to the reasons above. More importantly, this study didn't influence pooled HRs of TET2 mutation for the OS significantly. With regard to patients under 65 years of age, the pooled HRs for EFS decreased from 1.724 to 1.429 with a lower heterogeneity after the study of Cher and colleagues was excluded. The sample size of cases with TET2 mutation from Cher's study was the smallest, which might be expected to result in the heterogeneity.
In patients with CN-AML under 65 years of age, significant heterogeneity in pooled HRs for OS was from Damm's study. Actually, this study demonstrated a totally different result opposed to other two studies confirming the unfavorable impact of TET2 mutation in this cohort. The relatively lower percentage (6.75\%) and fewer cases (11 cases) with TET2 mutation might be the reasons for the bias.

As for patients in ELN intermediate-Irisk group, the study of Gaidzik and colleagues could account for a part of the significant heterogeneity in pooled ORs for CR rate and the combined ORs decreased to 0.809 from 1.120 with this study excluded. The cohort in Gaidzik's study had an age range from 18 to 60 years, nevertheless the patients from the other two studies had more broad age range (Ahn: from 15 to 84 years; Metzeler: from 18 to 83 years), including patients over 60 years old. Therefore the relatively younger patient cohort could explain the heterogeneity in OR for CR rate and might be the cause of relatively higher CR rate in Gaidzik's study. The study of Gaidzik and colleagues had a large sample size of cases with TET2 mutation and a relatively long follow-up period. Hence, this study should be reserved 


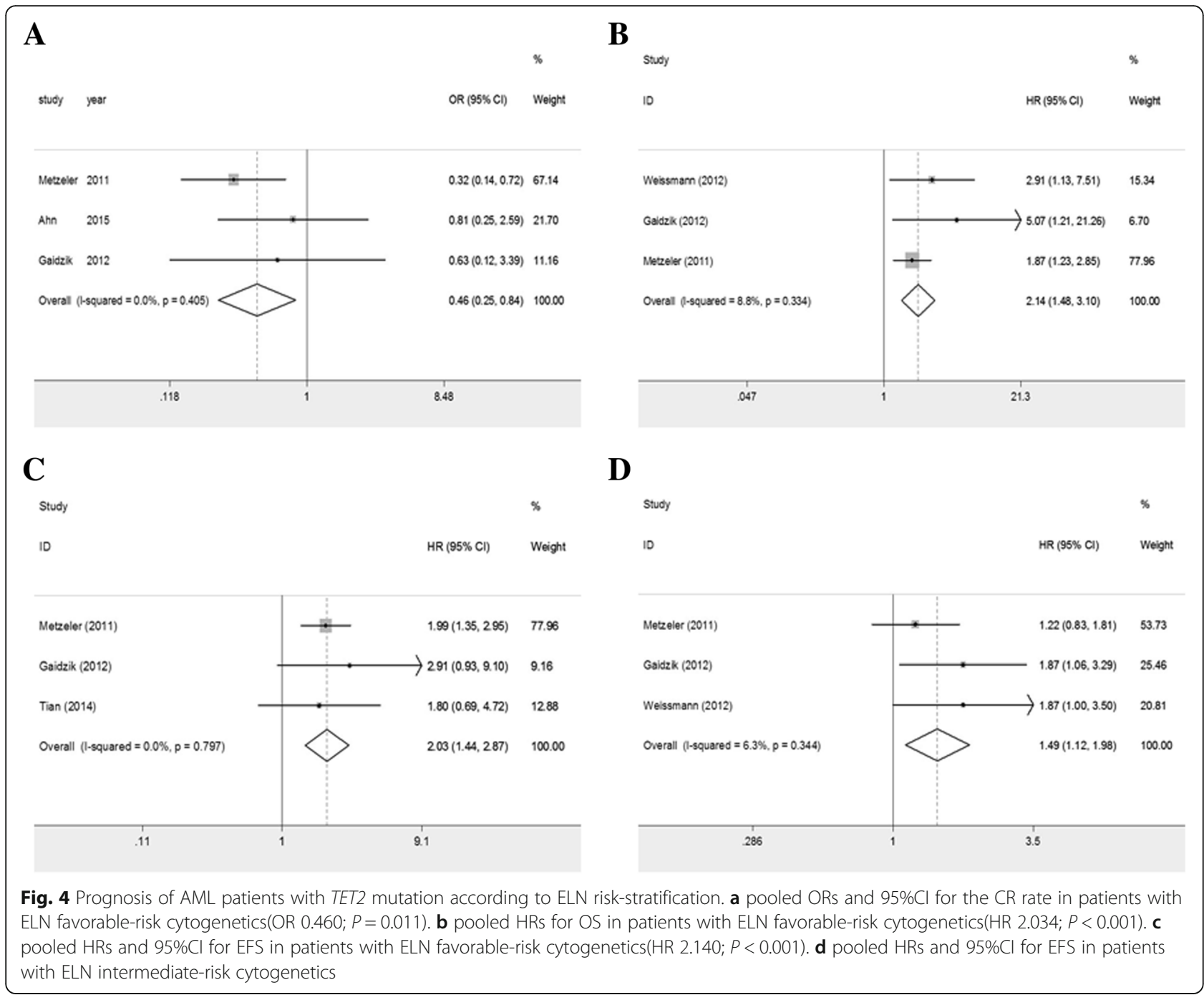

and the impact on CR rate of TET2 mutation in patients with ELN intermediate-Irisk cytogenetics remained unclear.

\section{Subgroup analyses}

As we stated previously, we performed subgroup analyses to further assess the prognosis of TET2 mutation on EFS in AML patients. We found that publication year, data types, regions of samples and study cohorts had no influence on OS for mutant TET2. In aspect of detection method, the studies using next-generation sequencing method had more significant results compared with those using direct sequencing method (Table 2). Direct sequencing couldn't detect all the mutated spots and sometimes might miss the real TET2 mutation, while next-generation sequencing skill could detect all the genome, more sensitive and precise than direct sequencing, so it could reduce the incident of false-negative events and exactly represent the adverse impact of TET2 mutation.

\section{Publication bias}

We performed Egger tests and Begg tests to assess publication bias in this study (Additional file 3: Table S6). There existed no publication bias in other results in both Egger test and Begg test (Additional file 1: Figure S4A-S4D).

\section{Comparing results from fixed effect model with those from random effect model}

With respect to OS and EFS for mutant TET2, HRs and $95 \% \mathrm{CI}$ without heterogeneity $\left(\mathrm{I}^{2}=0.00 \%\right)$ from the fixed effect model were the same as those from the random effect model. HRs and 95\%CI with heterogeneity $\left(\mathrm{I}^{2}>\right.$ $0.00 \%$ ) from the fixed effect model had slight changes compared with those from the random effect model but these changes did not influence the prognosis analyses. In addition, ORs and 95\%CI for CR rate were slightly changed from the fixed effect model to the random effect model no matter whether there existed 
heterogeneity or not, which had no impact on prognosis analyses (Additional file 3: Table S7).

\section{Discussion}

\section{Major findings}

In this study, TET2 mutations exhibited markedly unfavorable impacts on prognosis of AML patients. $\mathrm{Pa}-$ tients with TET2 mutations had reduced OS (HR: 1.386; $P<0.001)$ compared with those with wild type TET2. We also observed that mutant TET2 had unfavorable impacts on OS (HR: 1.310, $P=0.051$ ) and EFS (HR: $1.429, P=0.027)$ in patients under 65 years of age. Although $95 \% \mathrm{CI}$ for OS covered 1.000 , the $P$ value was slightly over 0.050 and still conferred an adverse trend for OS. In addition, TET2 mutations could also significantly reduce the OS of patients with IR-AML (HR: $1.474, P<0.001$ ).

Likewise, the same adverse influences of TET2 mutations could be observed in patients with CN-AML (HR for OS: 1.425, $P<0.001$; EFS: $1.450, P<0.001)$. Among CN-AML patients, patients under 65 years of age harboring TET2 mutations had more reduced OS (HR: 1.999, $P=0.001)$ and EFS(HR: 1.741, $P=0.005)$ compared with those harboring wild type.

As patients with CN-AML could be subdivided into a favorable group (ELN favorable-risk group) and an unfavorable-risk group (ELN intermediate-Igroup), we then evaluated the prognostic influence of TET2 mutation on patients from different ELN subgroups. Among ELN favorable-risk group, TET2 mutations led to significantly decreased CR rate (OR: $0.460, P=0.011)$ and reduced survival (HR for EFS: 2.140, $P<0.001$; HR for OS: 2.034, $P<0.001$ ), which showed the adverse impact of TET2 mutation in this group. As for patients in ELN intermediate-Igroup, because of the significant heterogeneity, we performed a sensitivity analysis and found that recombined ORs for CR rate was 0.809 after excluding Gaidzik's study but still didn't reach statistically significance. We had discussed that the diverse age range might be the cause for the higher $\mathrm{CR}$ rate of patients from Gaidzik's study. According to several studies, age could be an independent prognostic factor in AML, and younger patients had a better treatment outcome compared with older patients. However, this study shouldn't be excluded due to the large sample size of cases with mutant TET2 (23.3\%) and the relatively long follow-up period in this study. Therefore, the result needs to be confirmed further. In addition, mutant TET2 had an unfavorable impact on EFS of patients in ELN intermediate-Igroup (HR: 1.487, $P<0.001$ ). Because the hot spots of TET2 mutations were not explored in the whole exon, we were not able to evaluate the prognostic impact of the specific mutated spot of TET2.
The emergence of TET2 mutations represents an early event in the progression from normal hematopoiesis to AML. Nonetheless, some patients with mutations in AML-associated genes such as TET2 don't develop AML. Many researchers proposed a conception of clonal hematopoiesis of indeterminate potential, or CHIP, which was linked to a very low rate of conversion to AML and was also age-related like TET2 mutations. However, it's possible that all clones in CHIP would generate AML if given enough time and additional hits of genetic mutations. That might account for this relationship between TET2 mutations and elder age.

Our study explored the adverse prognostic effect of mutant TET2 on AML patients based on aspects of patients cohort, age, and risk stratification, which can bring great benefits to prognosis evaluation and therapy strategy guidance. In Itzykson's study, azacitidine conferred a better response rate on patients with myelodysplastic syndromes and low blast count AML, which showed TET2 mutations' predictive value of response to hypomethylated agents [34]. We also validated the superiority of next-generation sequencing skill compared with direct sequencing skill from the subgroup analyses of EFS in AML patients, which could predict the promising prospect of next-generation sequencing skill in gene detection due to its precision and a high sensitivity.

\section{Comparison with other analyses}

Our study confirmed the adverse effects of mutant TET2 on prognosis of AML patients in accordance with another meta-analysis which was operated by Liu Wenjian with 8 studies included [11]. Both studies evaluated OS and EFS of patients from the entire AML, CN-AML, ELN favorable-risk group and intermediate-Igroup. Our meta analysis included 16 studies containing 4577 cases altogether, more stable and more reliable than the previous analysis. Our research was built on a broad population involving many regions including America, Asia, Europe, which meant utilization.

Besides, we summarized the correlation of TET2 mutations and several major clinical features involving age, laboratory parameters, FAB subtypes, cytogenetics and other genetic alterations. We noted that mutant TET2 correlated with older age, higher WBC count, lower platelet count, intermediate-risk cytogenetics, mutations in NPM1, DNMT3A and ASXL1, and were mutually excluded with favorable-risk cytogenetics and $I D H$ mutations.

More importantly, we explored more about prognostic influences of mutant TET2 on survival and treatment outcomes. TET2 mutation had negative impacts on $\mathrm{CR}$ rate (OR: $0.460, P=0.011)$ and OS (HR: $2.034, P<0.001)$ within patients in ELN favorable-risk group. Nevertheless, among patients with AML, CN-AML and those in 
ELN intermediate-Igroup, TET2 mutation had no impact on $\mathrm{CR}$ rate. We also investigated the correlation of TET2 mutation with OS and EFS of patients under 65 years of age, and that mutant TET2 was linked to unfavorable OS and EFS in this kind of patients cohort with AML (HR for OS: 1.310, $P=0.051$; EFS:1.429, $P=$ 0.027 ) and CN-AML (HR for OS: 1.999, $P=0.001$; EFS: 1.741, $P=0.005)$. We also found the adverse impact of mutant TET2 on OS (HR: $1.474, P<0.001$ ) in patients with IR-AML. All the findings above were not presented in previous meta analysis.

In addition, we operated subgroup analyses to evaluate the stability of our results deeply. We found that next-generation sequencing skill could lead to a more significant HR for EFS of TET2 mutation.

\section{Limitations of our study}

Regardless of the fact that we made the effort to perfect our study, there still existed several limitations. To start with, we only brought studies in English and Chinese into our research, with studies in other kinds of languages omitted, which might influence the real consequences. Secondly, all the studies included were retrospective studies, which made it difficult control the selective criteria and guarantee homogeneity of chosen studies. Thirdly, although some of studies provided precious data of $\mathrm{HRs}$ and $95 \% \mathrm{CI}$ in multivariate analyses, there were also some studies only providing data from univariate analyses, even some data needed extracting from Kaplan-Meier survival curves, all of which might reduce the stability of the results. Next, various studies included in our meta analysis didn't provide the specific information about karyotype, WHO subtype, FAB subtype, genetic aberration and survival period of each patient. Therefore we couldn't investigate the relationship between the impact of TET2 mutations on prognosis and the factors above. Finally, we were not capable of evaluate the effect of mutant TET2 on prognosis in patients over 65 years old due to the data deficiency, which made it difficult to compare the impact on survival of TET2 mutation between different age groups. In addition, some forest graphs in our analysis only contained 3 individual studies, which appeared to compromise the overall accuracy. Nonetheless, we rigidly operated the accurate procedures of meta analysis and that all included studies were evaluated of high quality. What's more, after omitting the study of high heterogeneity, the width of confidence interval reduced, which meant that the accuracy actually increased.

\section{Conclusions}

Although there were still controversies over the clinical significance of TET2 mutations according to different conclusions from a variety of studies, we confirmed the unfavorable impacts of TET2 mutations on response to therapy and prognosis in AML stratified by age or cytogenetics. Research on TET2 mutations will provide more benefits for risk stratification, prognosis judgment and therapy guideline. We believe that further study of genetic aberrances and the development of next-generation sequencing skill will promote our perception of malignant hematologic neoplasms in development mechanism and risk factors.

\section{Additional files}

\begin{abstract}
Additional file 1: Figure S1: Title of data: Influences of TET2 mutation on prognosis in AML patients. Description of data: forest plots of pooled HRs and $95 \% \mathrm{Cl}$ for OS or EFS in AML patients. Figure S2: Title of data: Influences of TET2 mutation on prognosis in CN-AML patients. Description of data: forest plots of pooled HRs and $95 \% \mathrm{Cl}$ for OS or EFS in CN-AML patients. Figure S3: Title of data: Influences of TET2 mutation on prognosis in patients with ELN intermediate-Irisk cytogenetics. Description of data: forest plots of pooled HRs and $95 \% \mathrm{Cl}$ for OS or EFS of patients with ELN intermediate-Irisk cytogenetics. Figure S4: Title of data: Funnel plot for publication bias test of TET2 mutation in EFS. (DOC $916 \mathrm{~kb}$ )

Additional file 2: Table S1. Specific mutational spots of TET2 gene collected from 11 studies. (XLS 79 kb)

Additional file 3: Table S2: Title of data: Patients characteristics from the studies according to TET2 gene status. Table S3: Title of data: The relationship between TET2 mutation and FAB subtypes. Table S4: Title of data: The relationship between TET2 mutation and cytogenetics. Table S5: Title of data: The relationship between TET2 mutation and other genetic aberrations. Table S6: Title of data: The results of Egger test and Begg test to evaluate publication bias. Table S7: Title of data: The results comparison between the fixed effect model and the random effect model. (DOC 356 kb)
\end{abstract}

\section{Abbreviations}

5-hmc: 5-hydroxymethyl-cytosine; 5-mc: 5-methyl-cytosine; AML: Acute myeloid leukemia; CHIP: Clonal hematopoiesis of indeterminate potential; Cl: Confidence interval; CN-AML: AML with normal cytogenetics; EFS: Eventfree survival; HR: Hazard ratio; IR-AML: AML with intermediate-risk cytogenetics; OR: Odds ratio; OS: Overall survival; WBC: White blood cell

\section{Acknowledgements}

Not applicable

\section{Funding}

This study is supported by the National Science Foundation of China (81670135 and 81870109 to X-N G). The money was used to cover publication fees. No member of the foundation was involved in study design, data analysis and writing of the manuscript.

\section{Availability of data and materials}

All data generated or analyzed during this study are reflected in the present published article and its supplementary information files.

\section{Authors' contributions}

Conception of the work: RQW, XNG and LY. Reference collection: RQW. Data analysis: RQW and XNG. Manuscript drafting: RQW, XNG and LY. Critically revising: $R Q W, X N G$ and $L Y$. The authors contributed equally to this article. All authors read and approved the final manuscript.

Ethics approval and consent to participate Not applicable

Consent for publication

Not applicable 


\section{Competing interests}

The authors declare that they have no competing interests.

\section{Publisher's Note}

Springer Nature remains neutral with regard to jurisdictional claims in published maps and institutional affiliations.

\section{Author details}

${ }^{1}$ Department of Hematology, Chinese PLA General Hospital, Medical Schoo of Chinese PLA, 28 Fuxing Road, Beijing 100853, China. ${ }^{2}$ Medicine School, Nankai University, 94 Weijin Road, Tianjin 300071, China. ${ }^{3}$ Department of Hematology-Oncology, Carson International Cancer Center, Shenzhen University General Hospital, Shenzhen University Health Science Center, 1098 Xueyuan Avenue, Shenzhen 518060, China.

\section{Received: 5 August 2018 Accepted: 12 April 2019}

Published online: 25 April 2019

\section{References}

1. Siegel RL, Miller KD, Jemal A. Cancer statistics, 2017. CA Cancer J Clin. 2017; 67(1):7-30.

2. Grimwade D, Hills RK. Independent prognostic factors for AML outcome. Hematology Am Soc Hematol Educ Program. 2009:385-95.

3. Döhner $\mathrm{H}$, Estey $\mathrm{E}$, Grimwade $\mathrm{D}$, et al. Diagnosis and management of AML in adults: 2017 ELN recommendations from an international expert panel. Blood. 2017;129(4):424-47.

4. Ley TJ, Ding L, Walter MJ, et al. DNMT3A mutations in acute myeloid leukemia. N Engl J Med. 2010;363(25):2424-33.

5. Shivarov V, Gueorguieva R, Stoimenov A, et al. DNMT3A mutation is a poor prognosis biomarker in AML: results of a meta-analysis of $4500 \mathrm{AML}$ patients. Leuk Res. 2013;37(11):1445-50.

6. Metzeler $\mathrm{KH}$, Becker $\mathrm{H}$, Maharry K, et al. ASXL1 mutations identify a high-risk subgroup of older patients with primary cytogenetically normal AML within the ELN Favorable genetic category. Blood. 2011;118(26):6920-9.

7. Paschka P, Schlenk RF, Gaidzik VI, et al. ASXL1 mutations in younger adult patients with acute myeloid leukemia: a study by the German-Austrian acute myeloid leukemia study group. Haematological. 2015;100(3):324-30.

8. Xu Q, Li Y, Lv N, et al. Correlation between Isocitrate dehydrogenase gene aberrations and prognosis of patients with acute myeloid leukemia: a systematic review and Meta-analysis. Clin Cancer Res. 2017 Aug 1;23(15): 4511-22.

9. Kao HW, Liang DC, Kuo MC, et al. High frequency of additional gene mutations in acute myeloid leukemia with MLL partial tandem duplication: DNMT3A mutation is associated with poor prognosis. Oncotarget. 2015; 6(32):33217-25.

10. Patel JP, Gönen M, Figueroa ME, et al. Prognostic relevance of integrated genetic profiling in acute myeloid leukemia. N Engl J Med. 2012;366(12): 1079-89.

11. Liu WJ, Tan XH, Luo XP, et al. Prognostic significance of TET methylcytosine dioxygenase 2 (TET2) gene mutations in adult patients with acute myeloid leukemia: a meta-analysis. Leuk Lymphoma. 2014;55(12):2691-8.

12. Ko M, Huang $Y$, Jankowska AM, et al. Impaired hydroxylation of 5methylcytosine in myeloid cancers with mutant TET2. Nature. 2010; 468(7325):839-43.

13. Mayer J, Arthur C, Delaunay J, et al. Multivariate and subgroup analyses of a randomized, multinational, phase 3 trial of decitabine vs treatment choice of supportive care or cytarabine in older patients with newly diagnosed acute myeloid leukemia and poor- or intermediate-risk cytogenetics. BMC Cancer. 2014;14:69.

14. Jiang $X$, Wang $Z$, Ding B, et al. The hypomethylating agent decitabine prior to chemotherapy improves the therapy efficacy in refractory/relapsed acute myeloid leukemia patients. Oncotarget. 2015;6(32):33612-22.

15. Fenaux P, Mufti GJ, Hellström-Lindberg $E$, et al. Azacitidine prolongs overall survival compared with conventional care regimens in elderly patients with low bone marrow blast count acute myeloid leukemia. J Clin Oncol. 2010; 28(4):562-9.

16. Daver N, Cortes J, Kantarjian $\mathrm{H}$, et al. Acute myeloid leukemia: advancing clinical trials and promising therapeutics. Expert Rev Hematol. 2016;9(5):433-45.
17. Zhou Z, Zhang T, Li B, et al. Extracting and transforming of appropriate data of Meta-analysis in survival curve. Chin J Evid Based Cardiovasc Med. 2014; 6(3):243-7.

18. Perleth M, Langer G. GRADE quidelines: 7. Rating the quality of evidenceinconsistency. Z Evid Fortbild Qual Gesundhwes. 2012;106(12):733-44.

19. Zhang $T$, Zhong $W$, Zhang $S$, et al. Stata in assessing heterogeneity in Metaanalysis. J Evid Based Med. 2008;8(4):231-4.

20. Ohgami RS, Ma L, Merker JD, et al. Next-generation sequencing of acute myeloid leukemia identifies the significance of TP53, U2AF1, ASXL1, and TET2 mutations. Mod Pathol. 2015;28(5):706-14.

21. Ahn JS, Kim HJ, Kim YK, et al. Adverse prognostic effect of homozygous TET2 mutation on the relapse risk of acute myeloid leukemia in patients of normal karyotype. Haematologica. 2015;100(9):e351-3.

22. Cher CY, Leung GM, Au CH, et al. Next-generation sequencing with a myeloid gene panel in core-binding factor AML showed KIT activation loop and TET2 mutations predictive of outcome. Blood Cancer J. 2016;6(7):e442.

23. Abdel-Wahab O, Mullally A, Hedvat C, et al. Genetic characterization of TET1, TET2, and TET3 alterations in myeloid malignancies. Blood. 2009; 114(1):144-7.

24. Metzeler $\mathrm{KH}$, Maharry K, Radmacher MD, et al. TET2 mutations improve the new European LeukemiaNet risk classification of acute myeloid leukemia: a Cancer and leukemia group B study. J Clin Oncol. 2011;29(10):1373-81.

25. Chou WC, Chou SC, Liu CY, et al. TET2 mutation is an unfavorable prognostic factor in acute myeloid leukemia patients with intermediate-risk cytogenetics. Blood. 2011;118(14):3803-10.

26. Gaidzik VI, Paschka P, Späth D, et al. TET2 mutations in acute myeloid leukemia (AML): results from a comprehensive genetic and clinical analysis of the AML study group. J Clin Oncol. 2012;30(12):1350-7.

27. Weissmann S, Alpermann T, Grossmann V, et al. Landscape of TET2 mutations in acute myeloid leukemia. Leukemia. 2012;26(5):934-42.

28. Damm F, Markus B, Thol F, et al. TET2 mutations in cytogenetically Normal acute myeloid leukemia: clinical implications and evolutionary patterns. Genes Chromosomes Cancer. 2014:53(10):824-32.

29. Nibourel O, Kosmider O, Cheok M, et al. Incidence and prognostic value of TET2 alterations in de novo acute myeloid leukemia achieving complete remission. Blood. 2010;116(7):1132-5.

30. Kosmider O, Delabesse E, De Mas VM, et al. TET2 mutations in secondary acute myeloid leukemias: a French retrospective study. Haematologica. 2011;96(7):1059-63.

31. Lin PH, Li HY, Fan SC, et al. A targeted next-generation sequencing in the molecular risk stratification of adult acute myeloid leukemia: implications for clinical practice. Cancer Med. 2017;6(2):349-60.

32. Renneville A, Abdelali RB, Chevret $\mathrm{S}$, et al. Clinical impact of gene mutations and lesions detected by SNP-array karyotyping in acute myeloid leukemia patients in the context of gemtuzumab ozogamicin treatment: results of the ALFA-0701 trial. Oncotarget. 2014;5(4):916-32.

33. Tian $X, X u Y, Y$ in J, et al. TET2 gene mutation is unfavorable prognostic factor in cytogenetically normal acute myeloid leukemia patients with NPM tand FLT3-ITD-mutations. Int J Hematol. 2014;100(1):96-104.

34. Itzykson R, Kosmider O, Cluzeau T, et al. Impact of TET2 mutations on response rate to azacitidine in myelodysplastic syndromes and low blast count acute myeloid leukemias. Leukemia. 2011;25(7):1147-52.

Ready to submit your research? Choose BMC and benefit from:

- fast, convenient online submission

- thorough peer review by experienced researchers in your field

- rapid publication on acceptance

- support for research data, including large and complex data types

- gold Open Access which fosters wider collaboration and increased citations

- maximum visibility for your research: over $100 \mathrm{M}$ website views per year

At $\mathrm{BMC}$, research is always in progress.

Learn more biomedcentral.com/submissions 